\title{
THE SURGICAL SEPARATION OF SIAMESE TWINS CONJOINED BY THE HEADS (CEPHALOPAGUS FRONTALIS) FOLLOWED BY NORMAL DEVELOPMENT
}

\author{
BY \\ MAITLAND BALDWIN and ANATOLE DEKABAN

\begin{abstract}
From the National Institute of Neurological Diseases and Blindness, National Institutes of Health, Public Health Service, U.S. Department of Health, Education and Welfare, Bethesda 14, Maryland
\end{abstract}

Human conjoined twins are rare. Various authors (Mortimer and Kirshbaum, 1942; Potter, 1952) give figures ranging from one in 60,000 to one in 85,000 births for various types of Siamese twins either alive or stillborn. In 117 conjoined twins, a series of which was compiled by Robertson (1953) from Taruffi's eight-volume study on heratology (Storia della Teratologia, Bologna, Regia Tipografia, 188194), thoracopagus was present in 86 , pygopagus in 22 , ischiopagus in seven, and cephalopagus in two only. From the analysis of these data it appears that the incidence of cephalopagus would be in the range of one in every two to four million births.

The only satisfactory treatment of cephalopagous twins is surgical separation. This, however, presents enormous technical difficulties and the number of surviving infants after such procedures are few. In the present communication we are therefore reporting an instance of Siamese twins who were conjoined by the frontal regions of the heads and who continue to develop normally after separation.

\section{Case Report}

Virginia and Tresea, 2-month-old female twins conjoined by the heads, were admitted to the National Institute of Neurological Diseases and Blindness for study and possible treatment in October, 1956. The mother was 21 years of age at the time of delivery. She has always been healthy. There were no multiple births in her family nor any evidence of neurological or developmental abnormalities. Her menstruation has always been regular. She has had three pregnancies, all resulting in live births. The first child, a girl 4 years of age, and the second child, a boy, 28 months of age, are normal in all respects.

The father died of rheumatic heart disease at the age of 39 years three months before the twins were born. There were no known instances of congenital malformation or any neurological condition in his family. One of the paternal uncles has dissimilar twins.

Present Pregnancy.-The mother received regular prenatal care from the second month of gestation. During the first two trimesters she was subject to nausea and minor headaches but no vomiting. About three weeks before the delivery the membranes ruptured spontaneously and approximately a quart of fluid escaped. She was admitted to hospital for a few days and then remained in bed at home having periodic minor uterine contractions. She was re-admitted to the hospital in Elizabethton, Tennessee, on August 9, 1956, and three hours later female Siamese twins were delivered. The total birth weight of the conjoined twins was $3.5 \mathrm{~kg}$. The mother had general anaesthesia and does not know the details of the delivery nor the immediate state of the infants. She was told by the doctor that the second twin, who was slightly smaller (subsequently named Tresea), had to be resuscitated.

According to the physician attending the delivery there were two umbilical cords, one placenta, one chorion, and two amnions.

After two weeks in the hospital the twins were discharged home and for the next two weeks the mother fed them using a dropper. From the age of 1 month they were put on a bottle. In spite of great difficulty with feeding and general care, the mother had them at home until they were 2 months old.

Examination of the Twins at 2 Months of Age.-The infants were joined by the frontal and vertical regions in such a fashion that the predominantly right side of the head of one twin was in union with the predominantly right side of the other twin. In this way they appeared in mirror position to each other although slightly to the left $(3 \mathrm{~cm}$.) from the mid-sagittal planes (Figs. 1 and 2 ). The anterior fontanelles were partly open and partly involved in the bony union. The right orbital region and right eye were in close apposition, and when the infants were put in a parallel position the eyes were slightly compressed. The joined areas were in firm bony union. Tresea's joining part of the head appeared to telescope into Virginia's head forming a sort of coning (Figs. 3 and 4). The circumference of the conjoined area was $24 \mathrm{~cm}$. The total weight of both twins was $4 \mathrm{~kg}$. The state of nourishment and general physical conditions were good. They both took their feeds well. There was no evidence of other congenital abnormalities and their internal organs were normal. It was obvious that most 


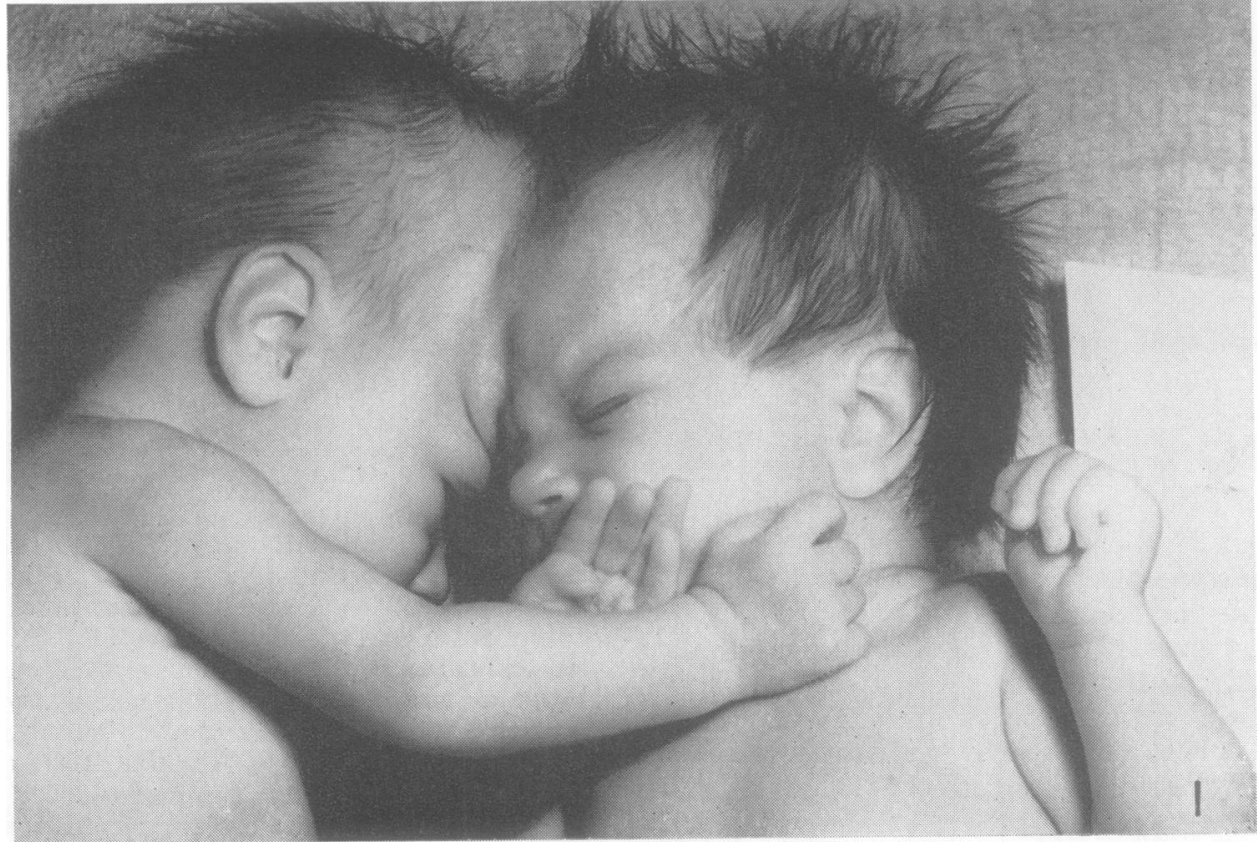

FIG. 1.-Siamese twins joined by the frontal region of their heads. The infant on the right is Virginia; the one on the left is Tresea.

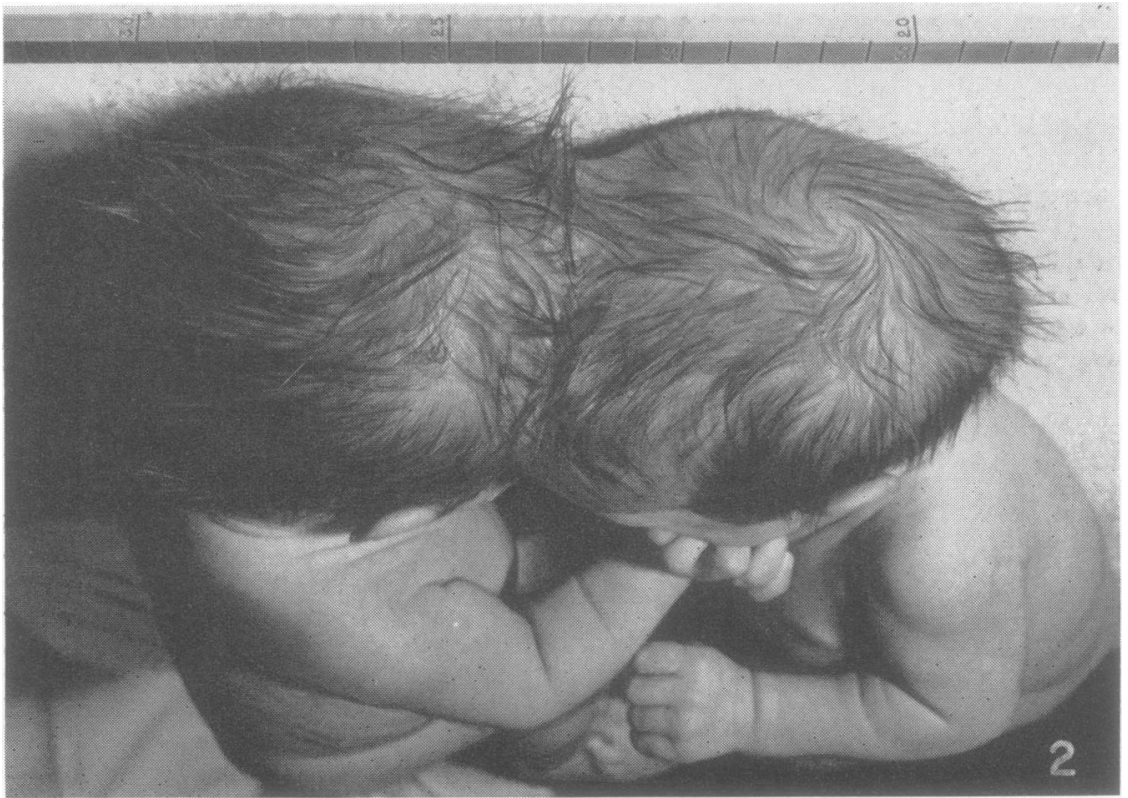

Fig. 2.-The fusion of heads extends almost throughout the transverse diameter. Slight lateral shift of the otherwise mirror position of heads can be noted. 
of the physiological functions of the infants were dissociated. One could be asleep while the other was awake and even crying. The rectal temperatures showed minor differences and also their pulse rates and respiration rhythms differed.

Virginia.--Virginia was the slightly bigger twin. Her head circumference, from the occiput to the top of the union at the vertex, was $34.5 \mathrm{~cm}$. The bitemporal diameter was $8.5 \mathrm{~cm}$., the antero-posterior $11.6 \mathrm{~cm}$., and the vertical $7 \cdot 2 \mathrm{~cm}$. The chest circumference was $32 \cdot 0 \mathrm{~cm}$. She responded in the normal way to a flashing light in her eyes by tightening her eyelids and by following the lesser intensity of light to the left side and up. The fundoscopic examination showed normal discs and retinae. The pupils were equal and reacted to light. Both eyeballs showed a moderate degree of internal squinting and the right palpebral fissure appeared narrowed and compressed as a result of close approximation by the corresponding regions of their foreheads. There was no nystagmus. She responded to gentle ringing of a bell by a decrease in activity. The rest of the cranial nerves were normal. She showed vigorous spontaneous movements of all four extremities in all joints. She responded normally to painful stimuli. There was no evidence of tremors or abnormal involuntary movements. The tendon reflexes were all present and equal. The Moro reflex was fully developed and symmetrical. Tonic neck reflexes could not be tested. Hand and toe grasp reactions were well developed on both sides. She was able to retain briefly a toy inserted in either hand and her hands were predominantly open.

Laboratory Tests.-The blood group was $0, \mathrm{Rh}$ positive. Haemoglobin was $11.9 \mathrm{~g}$. The urine was normal $\left(\mathrm{CO}_{2}\right.$ content $28 \mathrm{mEq}$./1. serum chlorides $105 \mathrm{mEq}$./1., calcium $9.4 \mathrm{mEq} . / \mathrm{l}$., potassium $4.8 \mathrm{mEq}$./1., sodium $140 \mathrm{mEq}$./1.). A radiological examination showed a normal chest and normal size of abdominal organs. There were no congenital malformations or other abnormalities in the skeletal structure. A radiograph of the skull showed that the frontal region, predominantly on the right side, was in junction with the corresponding bony parts of the co-twin (Figs. 3 and 4). Even with the help of laminograms it was not possible to estimate the precise size of the bony defect between the adjacent two brains. An approximate estimation showed it to be about $5 \mathrm{~cm}$. in diameter.

Tresea.-Tresea was the slightly smaller twin. Her head circumference from the occiput to the top of the union at the vertex was $33.5 \mathrm{~cm}$. The bitemporal diameter was $8.4 \mathrm{~cm}$., the antero-posterior $11.4 \mathrm{~cm}$., and the vertical $7 \cdot 8 \mathrm{~cm}$. Her chest circumference was $29.5 \mathrm{~cm}$. She followed light to the left and up and tightened her eyelids to a strong flashing light. Fundoscopic examination showed normal discs and retinae. The pupils were equal and reacted to light. There was a bilateral internal squint, more pronounced on the left. The palpebral fissure on the right was narrowed as a result of pressure by the excess of skin below the line of bony junction. There was no nystagmus. She responded to auditory stimuli by decreasing her activity. The facial sensation to pain and corneal reflexes was normal.

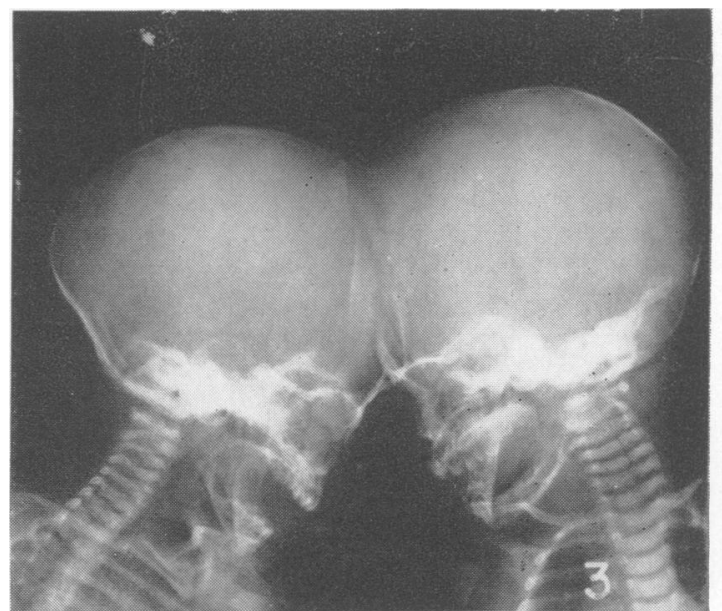

FIG. 3.-Lateral skull radiograph (Tresea is on the left); slight telescoping of the frontal region into the head of Virginia (right) can be noted.

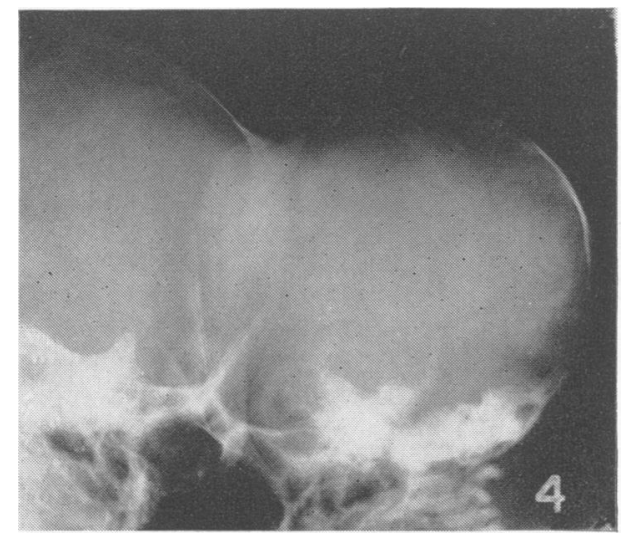

FIG. 4.-Oblique skull radiograph (Virginia is on the left).

The swallowing mechanism, as well as the size, shape, and movements of the tongue were normal. The muscle tone was normal for her age. She showed vigorous movements of all four extremities in all joints spontaneously and as a withdrawal reflex to nociceptive stimuli. There was no evidence of tremors or of abnormal involuntary movements. The tendon reflexes were all present and equal and the plantars were mainly flexor. The abdominal reflexes were present and equal. The sucking and Moro reflexes were well developed. Hand and toe grasp reactions on both sides were equal. She was able to retain very briefly a toy inserted in either hand and her hands were predominantly open.

Laboratory Tests.-The blood group was 0 , Rh positive. Haemoglobin was $11.4 \mathrm{~g}$. The urine was normal $\left(\mathrm{CO}_{2}\right.$ content $27 \mathrm{mEq}$./1., serum chlorides $100 \cdot 2 \mathrm{mEq}$./1., calcium $9.4 \mathrm{mEq}$./1., potassium $5.2 \mathrm{mEq}$./1., and sodium $139 \mathrm{mEq}$./1.). Radiological examination showed clear lungs, and a normal position and size of the heart and 
liver. There were no abnormalities in the skeletal structures. The description of the skull radiographs is similar to that of Virginia (Figs. 3 and 4).

Clinical Diagnosis. - This was cephalopagus frontalis with firm bony union of $24 \mathrm{~cm}$. in circumference. The brains were considered as probably separate, and the dura between the two corresponding parts of the brain was thought to be either absent, the two leaves fused, or separate. The possibility of the blood vessels crossing from one brain to the other was entertained.

It was difficult to care for the infants. Also they seemed to be in apparent discomfort when lifted to an upright position. The sleep of one twin was frequently interfered with by the crying of the other twin. Clearly, their normal development would have suffered if they were left joined for a longer time. Also, any infection in one of the twins would lead to serious consequences for both of them. For these reasons early surgical separation appeared to be the only logical solution. Following detailed consideration of all available data, it was decided that a surgical attempt should be made without preliminary exhaustive tests, such as ventriculograms and arteriograms, in order to avoid any possible complications of delay in separating them.

Operative Procedures.-With the assumption that surgical interference should be minimal, it was decided that the separation would be attempted in two stages and that these operations would not include plastic procedures designed to provide "scalp flaps" to cover the exposed areas of both brains.

The first-stage operation was performed when the twins were 3 months old, on November 9, 1956. After the skin incision over one-half of the junction, the rongeurs were used to separate the bony union. After the dura was incised, a portion of the underlying cortex was exposed. This consisted of small, narrow gyri and moderately deep sulci laced with fine blood vessels. The pia arachnoid overlying the cortex of both twins seemed continuous. After the usual haemostasis, the dura and skin were closed in layers. The common wound was dressed and the patients returned to the ward in good condition. The post-operative course was benign and stable throughout.

The general condition of both infants was good. Their total weight was $7 \cdot 7 \mathrm{~kg}$. When held in the arms in an upright position at 4 months of age their joined heads were stable and their backs were fairly straight. Virginia was slightly bigger and stronger than Tresea. She followed objects with her eyes and attempted head turning. Her hands were open and she grasped a toy with either hand and shook it vigorously. Tresea was, in general, slightly less vigorous although alert and following the surroundings with her eyes. She also grasped and moved toys with either hand and retained them for several minutes.

The second stage of the operation was performed on December 11, 1956. The twins were postured on dual tables with positions reversed, so that the previous surgical wound was underneath. The anaesthetic was a dministered by individual endotracheal tubes connected to the same machine. The main aim of this operation was to separate the twins and cover the resultant dural, bony, and skin defects. The separation was relatively uneventful. The skin was incised and retracted. The underlying bone was rongeured away along the exposed circumference so as to leave a channel approximately $2 \mathrm{~cm}$. in width. The exposed dura was then incised and carefully retracted on stay sutures. Next, the cortex was examined for a division. At first none was apparent. However, a close examination of the sulci revealed that one appeared deeper than the others. Further exploration showed that this was, in fact, the surface marking of a dividing fissure. This fissure was fused by a dense pia arachnoid bridge which required both sharp and blunt dissection. Approximately $4 \mathrm{~cm}$. in its depth the frontal lobes were fused directly by means of a fasciculus of white matter $2 \mathrm{~cm}$. in diameter. This bundle contained a lacy network of anastomosing vessels, one of which, an artery, had to be severed during the course of separation. Otherwise there was no need for any major circulatory interruption.

Once the brains were separated, the previous surgical wound was reopened from its inside and the twins lay separate on the tables. In accordance with our previous plan, the large wound defects were covered with reconstituted human dura and skin. (This tissue was supplied by the Tissue Bank of the U.S. Naval Medical Center after being prepared according to their technique.) We anticipated that the dural grafts might " take" but that the skin overlying them would almost certainly slough off. Nevertheless, the skin would provide a temporary covering. This somewhat unusual approach was adopted in order to decrease the risk resulting from many surgical operations. Obviously, the more orthodox plan would call for plastic procedures and thus additional surgery. The wounds were dressed and the patients returned to the ward in good condition. The post-operative course of each twin was not remarkable. For the first two weeks the wounds were dressed each day with bacitracinsaturated gauze. During this short period the skin grafts degenerated and the dural sheets became adherent to the surrounding dura of the infants. There was a considerable leakage of cerebrospinal fluid from the wound of each infant and Virginia developed Friedländer's bacillus meningitis. This infection cleared within three days on energetic treatment with antibiotics administered systemically and locally. After a month the dural grafts were observed to be sealing at their edges. Close examination revealed the presence of fine blood vessels at the junction and their radial growth towards the centre. At the beginning of the sixth month after separation of the twins, the dura was covered with four separate applications of calf embryo skin according to the technique developed by Sylvetti at the Tissue Bank of the U.S. Naval Medical Center. These skin grafts finally resulted in completely covering the external surface of the dura mater. At the age of 1 year the surface of the primary wound was completely epithelialized.

Examination of Twins at 6 Months of Age

Virginia.-Her general state of nourishment was satisfactory. Most of the dural graft had taken and the remainder of the operative area was granulating. Her 
weight was $4.6 \mathrm{~kg}$., length $61 \mathrm{~cm}$. She moved spontaneously and to nociceptive stimuli all the extremities, although the left extremities slightly less well than the right. Her tongue slightly deviated to the left and the left corner of the mouth was slightly lower. She had bilateral esotropia but the remainder of the cranial nerves were normal. The tendon reflexes on the left were brisker than on the right. Both plantars were predominantly flexor. On developmental examination her language and motor performance were at the level of 5 months of age. Her adaptive and personal-social behaviour was at the 6 months level.

Tresea.-The general state of nourishment was good. Her weight was $4.8 \mathrm{~kg}$., length $61 \cdot 1 \mathrm{~cm}$. The dural graft had partially taken but an area about $4 \mathrm{~cm}$. in diameter had to be left for granulation. She moved all her extremities spontaneously and in response to nociceptive stimuli. There was no evidence of focal weakness. Her vision, hearing, and fundi were normal but she had bilateral esotropia. All tendon reflexes were present and equal. On most occasions the big toes were flexor to plantar stimulation.

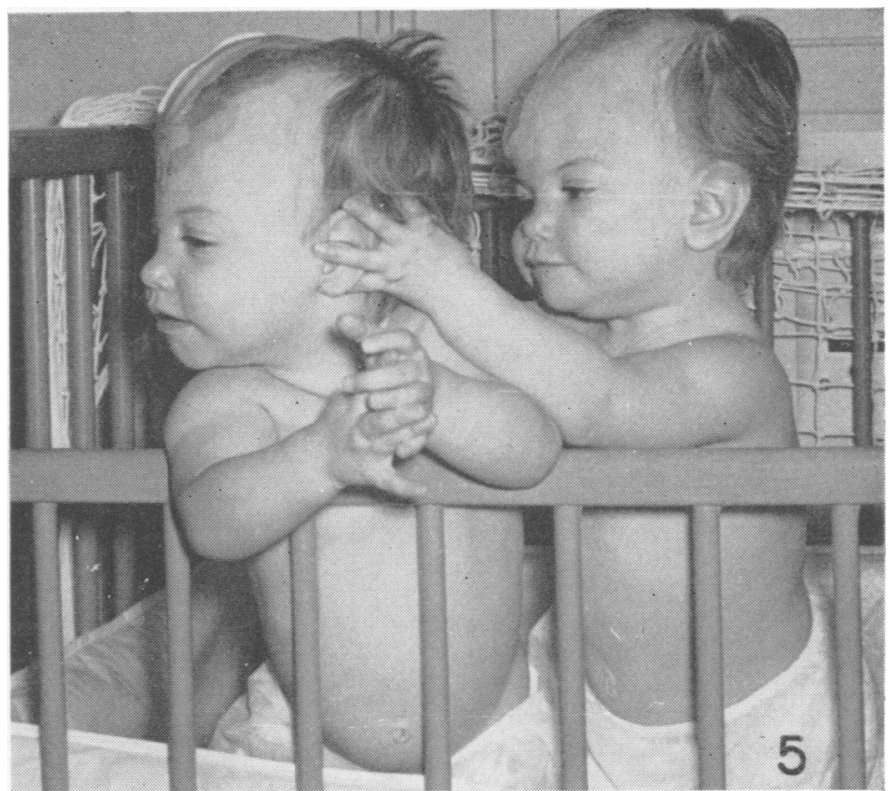

Fig. 5.-The separated babies are 9 months old. They appear healthy and playful. Both have a small dressing over the right frontal region. Tresea is on the left; Virginia is on the right.

On developmental examination her language and motor performance corresponded to the age level of 5 to 6 months. Her adaptive and personalsocial behaviour was at the level of 6 months.

\section{Examination of Twins at 9 Months of Age}

Virginia.- Her general condition and state of nourishment were good. Her weight was $6 \cdot 3 \mathrm{~kg}$., length $65 \mathrm{~cm}$. Only a small area of the operative site had not yet epithelialized. There was no demonstrable weakness of extremities although she used her left hand less skilfully than the right and the movements of the left fingers were less elaborate. There was still slight deviation of the tongue to the left and the left biceps and knee reflexes were slightly more active than the right. Both plantars were flexor. Language corresponded to the 8-month level and motor, adaptive, and personal-social behaviour to the 8 to 9 months level.

Tresea.-Her state of nourishment and general condition were normal. Her weight was $6.3 \mathrm{~kg}$., length $64 \mathrm{~cm}$. A considerable portion of the skin grafts had taken although there was still an area of about $4 \mathrm{~cm}$. in diameter which was not epithelialized. She used her extremities equally well on both sides and apart from persisting bilateral esotropia there were no neurological abnormalities. Her language corresponded to the level of 8 months. Her motor performance was at the 9-month level. Adaptive and personal-social behaviour was at the level of 8 to 9 months.

Examination of Twins at 1 Year of Age

Virginia.-The state of nourishment and general condition were good. Her weight was $7.5 \mathrm{~kg}$., length $70.5 \mathrm{~cm}$.
The skin over the operative site was completely epithelialized. The head circumference was $38.5 \mathrm{~cm}$., chest circumference was $42.5 \mathrm{~cm}$. Vision, peripheral vision, fundi, and hearing were normal. Her tongue moved in the midline and the remainder of the cranial nerves were normal except for persistent bilateral esotropia. The muscle tone and power were normal for her age and symmetrical. The movements of the left fingers were still slightly less elaborate and less skilful than the right, even if dominance is taken into account. There was no deficit in sensory perception or cerebellar coordination. All tendon reflexes were present and equal and the plantars were flexor on both sides. She was able to stand without support and to take a few steps alone. Her speech was that of 10 to 11 months. Her motor, adaptive, and personal-social behaviour were at the 12-month level.

Tresea.-Her general condition was good. Her weight was $7 \cdot 3 \mathrm{~kg}$. and length $70 \cdot 1 \mathrm{~cm}$. The skin defect over the operative area was completely epithelialized. Her head circumference was $38.5 \mathrm{~cm}$., chest circumference $41.0 \mathrm{~cm}$. Her vision, fundi, and hearing were normal. The remainder of the cranial nerves were normal except for the persistent bilateral esotropia. Skill of movements was good in all extremities. She perceived well sensory stimuli and there was no evidence of cerebellar incoordination. All tendon reflexes were present and equal and the plantars were flexor on both sides. She was able to stand without support for a few minutes and to walk a few steps alone. Speech corresponded to the level of 11 months, and motor, adaptive, and personal-social behaviour to the 12-month level. 


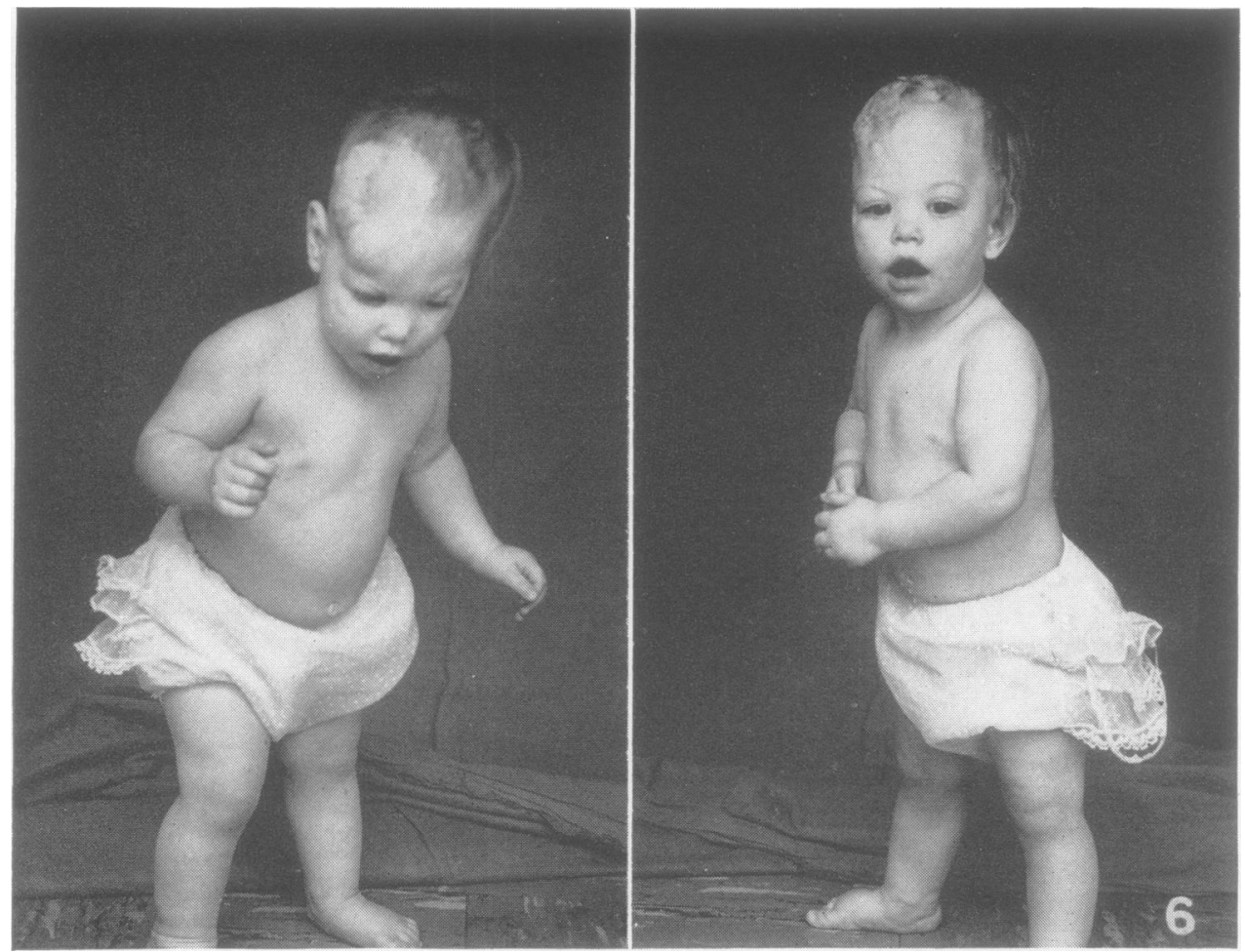

Fig. 6.-The babies are 1 year old. They can take several steps unaided and vocalize a few words. Virginia is on the left; Tresea is on the right.

\section{Discussion}

Most of the reports on Siamese twins joined by their heads relate to stillbirths or to viable infants surviving but a short time (Blumensaat, 1932; Mortimer and Kirshbaum, 1942; Gunter, 1946; Coulton, Hertig, and Long, 1947; Leinzinger and Scherrer, 1953; Haug and Leonhardt, 1955, and others).

The known instances when surgical separation of cephalopagous was attempted are only few. In 1928, Cameron described twin infants joined by the whole extent of the vertex of the skull. On the twelfth day of life an attempt at surgical separation was forced by the very rapid deterioration of one twin. Unfortunately, both twins died early in the course of the operation. Leiter (1932) reported cephalopagous twins in whom surgical separation was performed on the eighth day of life by sacrificing one of the twins. However, the other infant also died. Barbosa (1949) published a report on surgical separation of cephalopagous twins. One of the conjoined infants had associated other malformations, hypospadiasis and imperforate anus. The twins withstood the surgical separation but they both died three hours later. Robertson (1953) described a pair of twins conjoined by their heads. After a variety of tests, which included pneumoencephalography and arteriography, surgical separation was attempted but could not be completed because of the rapidly deteriorating condition of both infants. They both died at the age of 8 months, five months after surgical exploration. In 1953, Grossman, Sugar, Greeley, and Sadove reported on surgical separation of cephalopagous male twins. Since this was the first instance of a successful operative separation of cephalopagous twins it warrants more detailed description. Before the operation pneumoencephalography, arteriography, and sinography were carried out. After the skin grafts were prepared the first stage of the operation was performed at 10 months of age. This was followed by complete separation of the twins at 11 months of age. The brains were separate but the tributary veins drained to common dural sagittal sinuses, of which there appeared to be three. These sinuses were left with one twin and the tributary veins of the other twin were ligated. The latter twin died one month after the operation. His twin survives although his mental development seems retarded.

While our report was in preparation, Voris, 
Slaughter, Christian, and Cayia (1957) reported another successful separation of Siamese twins joined by the vertex. The dura mater was found to be present between the two conjoined heads. One of the twins developed a marked cerebral hernia and associated left hemiparesis; at the age of 28 months she could sit up alone and say a few words. The other twin talked well at 28 months of age and her progress was said to be satisfactory.

The disturbed morphogenesis leading to conjoined twins presents many interesting problems, most of which, however, cannot be answered definitely at the present time. Excessive speculation would probably obscure more than clarify the issue. The cause of this abnormality in humans is unknown. A few relevant experimental data will be referred to later. In so far as the early embryology is concerned certain information is available. As a starting point and also to provide the basis for discussion, one aspect already raised by the early embryologists needs to be stressed: the mechanism of the production of conjoined twins must be closely related to the mechanism of the formation of uniovular twinning.

Theoretically, uniovular twinning may occur during the following stages of development:

(1) Before or during the early morula stage (first few days after fertilization). This must be extremely rare if it does occur at all. Each of the twin embryos would have to be enveloped in separate chorion and amnion.

(2) During the stage of inner cell mass (blastocyst), approximately seven to 11 days of gestation. Monovular twinning occurs most frequently at this stage. The twins have a common chorion but separate amnions.

(3) During the stage of primitive ectoderm (less than 14 days of gestation), the twins would possess one common chorion and one common amnion. Such twins do occur, although very infrequently.

A conjoined pair of uniovular twins may be either the result of incomplete separation of the formative material or the result of subsequent fusion of once separate embryos. The former possibility will be considered first. It would follow from the above brief outline that if the twinning takes place at the inner cell mass stage and if the separation is complete, the circumstance marking the twinning stage is the presence of a common chorion but two separate amnions. At the inner cell mass stage all cells are pluripotential and after they become separated into two groups normal differentiation will follow in both of them. If the separation is not complete at one locus, development of two embryos will proceed but the tissue which develops from the unseparated cells will remain in junction in a symmetrical fashion.

If the twinning takes place at the stage of primitive ectoderm the mechanism is more complicated. It has been postulated that there exist two or more separate body organizers. Normally one gains complete control and the others are suppressed and finally disappear; in such an instance one embryo results. When, for some reason both organizers continue to be active, two primitive streaks develop and twin embryos result. It is easy to see that there may be a territory in which formative cells are under equal influence of both organizers. In such a case this region will be common to both twins and the joined parts will be symmetrical. The twins will be enveloped by one chorion and one amnion. It is well known (Coulton et al., 1947) that monoamniotic twins are frequently stillborn as a result of compression of the severely intertwined umbilical cords which lead to obstruction of the blood circulation. The possibility of the occurrence of conjoined twins as a result of subsequent fusion of the once separate embryos seems very remote, at least in symmetrical Siamese twins. In the first place the junction would be frequently haphazard and not of the mirror image type, as seen in the majority of cases. Secondly, contrary to the general findings, such abnormality could occur only in monoamniotic twins not separated by the intervening membranes. The experimental work of Mangold (1920) is of considerable interest. This investigator produced conjoined individuals in the salamander by pressing two zygotes together. Since this was a highly artificial situation and concerned achorionic and anamniotic animals it could hardly be applicable to humans or even lower mammals.

In general then, the most likely stage of development when symmetrical conjoined twins are formed is the period of inner cell mass; the probable mechanism is incomplete separation of formative cell material. The cause, both of twinning and of incomplete separation, is unknown. The experimental evidence points to the important role of various factors capable of delaying the process of differentiation at the critical stage (Stockard, 1921). In man, an aged ovum and an abnormal state of the oestrogenic hormone have been suggested, but any objective evidence is lacking.

\section{Development of the Twins after Separation}

The development of both our twins following their separation has been surprisingly good. They certainly had many handicaps, such as restricted activity and less chance than normal infants for contact with their environment, until they were 
separated at the age of 4 months. Then a long period of about four months of complete confinement first in isolates, then in cribs, when the operative wounds were in a dangerous state with leakage of the cerebrospinal fluid. It was not until they were 11 months old that the operative sites in the frontal regions were completely epithelialized. At the age of 1 year their general and mental development can be considered as being within the normal range. Tresea has been free of any abnormal neurological findings. Virginia shows a minimal decrease in skilled movements of the left hand but power is normal.

\section{Summary}

Siamese twins conjoined by their heads are rare. This malformation requires surgical separation if the patients are to survive beyond the stage of infancy. A detailed description of cephalopagous twins is given. The infants were born by natural means and were normal in all respects except for union of the heads. Their development and neurological status before the final surgical separation at the age of 4 months and during their subsequent course is described. Homeo- and hetero- grafts were used to cover the defect of soft tissue at the site of separation. Development of the infants at 1 year of age was normal.
The pathogenesis of Siamese twins is discussed in some detail.

Our thanks are due to the neurological and neurosurgical residents and nursing staff who cared for both patients. In addition we wish to express our appreciation for their generous help to Dr. Thomas Cone, chief pediatrician at the National Naval Medical Center, and to the tissue bank, National Naval Medical School. Details of the anaesthesia were described by Dr. Hall in a separate publication (1957). Miss S. Lewis, R.N., designed a dual table which considerably aided the surgical procedure.

\section{REFERENCES}

Barbosa, A. (1949). Rev. brasil. Cirurg., 18, 1047.

Blumensaat, C. (1932). Virchows Arch. path. Anat., 285, 140.

Cameron, H. C. (1928). Lancet, 1, 284.

Coulton, D., Hertig, A. T., and Long, W. N. (1947). Amer. J. Obstet. Gynec., 54, 119.

Grossman, H. J., Sugar, O. Greeley, P. W., and Sadove, M. S. (1953) J. Amer. med. Ass., 153, 201

Gunter, J. U. (1946). Amer. J. Path., 22, 855.

Hall, K. D., Merzig, J., and Norris, F. H. (1957). Anesthesiology, 18, 908 .

Haug, H., and Leonhardt, H. (1955). Anat. Anz., 101, 281.

Leinzinger, E., and Scherrer, H. (1953). Geburtsh. Frauenheilk. 13, 543 ,'

Leiter, K. (1932). Zbl. Gynäk., 56, 1644

Mangold, O. (1920). Arch. Entwickl.-Mech. Org., Berlin, 47, 249.

Mortimer, B., and Kirshbaum, J. D. (1942). Amer. J. Dis. Child.

Potter, E. L. (1952). Pathology of the Fetus and the Newborn. Year (ब) Book Publishers, Chicago.

Robertson, E. G. (1953). A.M.A. Arch. Neurol. Psychiat., 70, 189

Stockard, C. R. (1921). Amer. J. Anat., 28, 115 .
Voris, H. C., Slaughter, W. B., Christian, J. R., and Cayia, E. (1957). J. Neurosurg.. 14, 548. 